\title{
Sensing the upper and lower levels of the atmosphere during the 2009 equinoxes using GPS measurements
}

\author{
Wayan Suparta ${ }^{1, \star}$ \\ ${ }^{1}$ Universiti Kebangsaan Malaysia, Space Science Centre (ANGKASA), Institute of Climate Change, 43600 Bangi, Selangor, \\ Malaysia
}

Article history

Received March 30, 2013; accepted March 5, 2014.

Subject classification:

GPS TEC, PWV, Equinoxes, Conjugate points, Associations.

\begin{abstract}
This short-term work characterized the upper and lower levels of the atmosphere through Global Positioning System (GPS) measurements. The observations were conducted during the 2009 equinoxes from two pairs of conjugate polar observing stations: Husafell, Iceland (HUSA) and Resolute in Nunavut, Canada (RESO) and their conjugate pairs at Scott Base (SBA) and Syowa (SYOG) in Antarctica, respectively. The total electron content (TEC), an indicator of the upper atmosphere, and the precipitable water vapor (PWV), which served as the lower atmospheric response, were retrieved and analyzed. The results reveal a good relationship between TEC and PWV at each station during the onset day of the equinoxes, whereas an asymmetrical response was observed in the beginning of and after the equinoxes. In addition, the conjugate pairs were only consistent during the autumnal equinox. Thus, the high correlation was observed following the seasonal pattern for the onset day, while strong and moderate correlations were found only for the vernal equinox in Antarctica and the Arctic, respectively. This relationship reflects the fact that the intensity of solar activity during the solar minimum incident on the lower atmosphere through the conjugate points is associated with the variation of the Sun's seasonal cycle, whereas the TEC and PWV showed an opposite relationship.
\end{abstract}

\section{Introduction}

The use of the Global Positioning System (GPS) in a wide variety of applications has exploded in the last few years. With the advancement of GPS technology and the spread of the GPS network around the world to remote locations such as Antarctica, the application of GPS to tasks including monitoring atmosphere dynamics, positioning and tracking, meteorology, and geophysical surveying has become possible. Recently, GPS has become a powerful tool for quantifying the ionospheric total electron content (TEC) [e.g., Coco 1991, Wanninger 1993, Klobuchar 1996] and the at- mospheric precipitable water vapor content (PWV) [e.g., Bevis et al. 1994, Businger et al. 1996, Rocken et al. 1997] in a cost-effective manner with global coverage and superior temporal and spatial resolution. This application of GPS can improve our understanding of the mechanisms driving ionospheric irregularities and the evolution of water vapor, two important factors in the relationship between solar activity and our atmosphere. Many studies have shown that perturbations in the ionosphere are clearly related to solar activity [e.g., Perrone and Franceschi 1998, Liu et al. 2011]. However, the impact of the ionosphere on the dynamics of Earth's atmosphere is still debated, and the interaction between the ionosphere and the lower atmosphere remains poorly explained.

To give a clear picture of "upper atmosphere" and "lower atmosphere" in this study, a brief definition is given. Scientists have defined both terms in various ways. In the context of meteorology, the "lower atmosphere" may be described as extending from the planetary surface (the troposphere) to the lower stratosphere, where the daily weather evolves. Thus, "upper atmosphere" refers to the entire region above the troposphere, including the mesosphere, the ionosphere and the thermosphere, which are identified by their temperature structure, density, composition and degree of ionization. Alternatively, the atmosphere can be divided into two different strata, the neutral atmosphere and the ionosphere, by considering the propagation of radio waves, such as GPS signals. The neutral atmosphere layer consists of three temperature-delineated regions: the troposphere, the stratosphere and part of the mesosphere. This layer is often simply referred to as the troposphere because the troposphere's effects dominate 
radio wave propagation. Therefore, to the GPS researcher, the "troposphere" generally refers to the neutral atmosphere spanning the altitudes of 0 to $40 \mathrm{~km}$ [Gregorius and Blewitt 1999]. Thus, when speaking of the ionosphere, the term refers to anything above the troposphere layer, or the upper part of the atmosphere. According to the subdivisions of the atmosphere proposed by Seeber [1993], the ionosphere is a conducting layer of weakly ionized plasma in the Earth's upper atmosphere. It stretches from approximately 50 to 1500 $\mathrm{km}$ above the Earth's surface and contains a significant number of ionized particles, i.e., free electrons and positively charged ions. Technically, because the ionosphere is a dispersive region of the Earth's atmosphere, TEC is the parameter that most affects a GPS signal along its trajectory from each satellite to the observer. Thus, in this context, the term "upper atmosphere" refers to the ionosphere, which has characteristics that are substantially influenced by the Sun. Conversely, the term "lower atmosphere" refers to the troposphere, where PWV is the climatic parameter that significantly affects GPS signals.

Along with the upper atmosphere's characteristics, the seasonal behaviors of the ionosphere have been investigated for several decades, but the differences in the ionosphere between the March and September equinoxes are still open for discussion [Liu et al. 2010]. This work characterized the upper and lower levels of the atmosphere using measurements obtained from groundbased GPS receivers during the 2009 equinoxes. During the equinox periods, the Sun moves northwards along the ecliptic in March and southwards in September; the equinoxes are better understood as the times when the day and night last almost exactly 12 hours. Because the charged particles in the Earth's magnetosphere tend to be trapped on the same geomagnetic field-line [e.g., Dragt 1965], conjugate points between regions could be strongly affected by solar activity. Conjugate stations enable us to investigate the similarities and/or asymmetries of charged particle properties, as well as phenomena between the hemispheres [Suparta et al. 2009]. Although the altitude between $40 \mathrm{~km}$ and $100 \mathrm{~km}$ is complex, a possible link between the upper and lower levels of the atmosphere through the correlation between TEC and PWV at bipolar conjugate points is proposed. The analysis is assumed to be valid because the majority of the GPS signal delay occurs when the signal traverses the ionosphere and troposphere.

\section{Measurements and data analysis}

This study presents the characterization of solar activity and terrestrial response during the Vernal Equinox (VE) and Autumnal Equinox (AE) periods. Data collected during the 2009 campaign in Iceland coincided with a minimum of solar activity and were processed to clarify the interaction between the upper and lower atmospheres from a GPS perspective. The observation periods selected were March 6 to April 3 for VE and September 8 to October 6 for $\mathrm{AE}$ and were equivalent to two weeks before and after the onset days of the equinoxes. The onsets of $\mathrm{VE}$ and $\mathrm{AE}$ for 2009 occurred on March 20 at 11:44 UT and on September 22 at 21:18 UT, respectively. At these times, the earth receives more direct solar energy and most likely experiences less atmospheric filtering due to the shorter solar distance from the Earth. Accordingly, the observations of vertical TEC (TEC for simplicity) and PWV are conducted at two pairs of GPS stations located near magnetically conjugate points in the Polar Regions. The GPS stations shown in Figure 1 are located at Husafell station (HUSA) in Iceland and Canadian Resolute (Cornwallis Island) station (RESO), Nunavut.

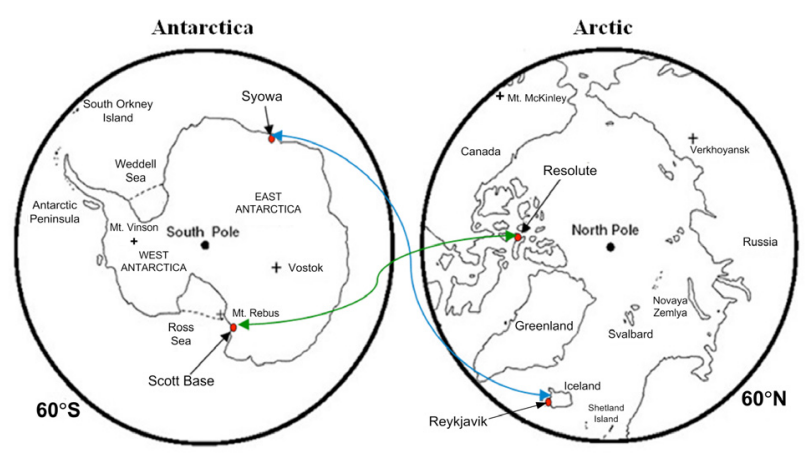

Figure 1. Location of GPS stations between the hemispheres with their conjugate points. The figures are adapted from http:/ /gdl.cdlr. strath.ac.uk/scotia/vserm/vserm0103.htm.

The two stations in the Northern Hemisphere (NH) form conjugate pairs with Syowa station (SYOG) and Scott Base station (SBA) in Antarctica (Southern Hemisphere, $\mathrm{SH})$, respectively. Table 1 presents the geographical and corrected geomagnetic coordinates of both GPS conjugate stations and the instrument setup. The difference in corrected geomagnetic latitude (CGMLat) between the conjugates was approximately 5-10 degrees. Despite the difference in CGMLat, HUSA-SYOG and SBA-RESO are ideal conjugate-pair observatories on the ground in the auroral zone, even though the real conjugate point is only found by the Aurora conjugate [Sato et al. 1998].

The GPS receiver at Husafell (HUSA), Iceland (Table 1) was installed on September 6, 2008. The GPS at HUSA consists of a GPS receiving system and a ground-based meteorological system. The GPS receiver consisted of a Leica GRX1200 GG Pro reference station from the Leica Geosystems, Switzerland with high dual-frequency performance, an AT504 choke-ring 


\begin{tabular}{|c|c|c|c|c|c|c|c|c|}
\hline $\begin{array}{l}\text { Station } \\
\text { (Region) }\end{array}$ & $\begin{array}{l}\text { Glat } \\
(\text { Deg })\end{array}$ & $\begin{array}{l}\text { Glon } \\
\text { (Deg) }\end{array}$ & $\begin{array}{l}\text { Height } \\
\text { (m) }\end{array}$ & $\begin{array}{l}\text { CGMlat } \\
\text { (Deg) }\end{array}$ & $\begin{array}{l}\text { CGMlon } \\
\text { (Deg) }\end{array}$ & $\begin{array}{l}\text { Type of GPS } \\
\text { receiver and } \\
\text { year installed }\end{array}$ & $\begin{array}{l}\text { Cutoff } \\
\text { elev. } \\
\text { angle }\end{array}$ & UTC Time \\
\hline HUSA & $64.67^{\circ} \mathrm{N}$ & $21.03^{\circ} \mathrm{W}$ & 220.20 & 61.55 & 100.57 & Leica GRX1200 & $15^{\circ}$ & $\mathrm{LT}=\mathrm{UT}$ \\
\hline (Arctic) & & & & & & Pro (2008) & & \\
\hline $\begin{array}{l}\text { SYOG } \\
\text { (Antarctica) }\end{array}$ & $69.00^{\circ} \mathrm{S}$ & $39.58^{\circ} \mathrm{E}$ & 45.00 & 66.31 & 72.22 & $\begin{array}{c}\text { Trimble 4000SSI } \\
\qquad(2002)\end{array}$ & $10^{\circ}$ & $\mathrm{LT}+12$ \\
\hline $\begin{array}{l}\text { SBA } \\
\text { (Antarctica) }\end{array}$ & $77.85^{\circ} \mathrm{S}$ & $166.76^{\circ} \mathrm{E}$ & 15.90 & 79.93 & 327.07 & $\begin{array}{c}\text { Trimble TS5700 } \\
\text { (2002) }\end{array}$ & $13^{\circ}$ & $\mathrm{LT}+12$ \\
\hline $\begin{array}{l}\text { RESO } \\
\text { (Arctic) }\end{array}$ & $74.69^{\circ} \mathrm{N}$ & $94.83^{\circ} \mathrm{W}$ & 19.98 & 82.83 & 323.11 & $\begin{array}{c}\text { Ashtech UZ-12 } \\
\text { (2006) }\end{array}$ & $0^{\circ}$ & $\mathrm{LT}-5$ \\
\hline
\end{tabular}

${ }^{*}$ D/IGRF stand for the Definite/International Geomagnetic Reference Field

Table 1. The geographic (G) and the corrected geomagnetic (CGM) coordinates (calculated based on the IGRF/DGRF model for year 2009) and instrument setup at two pairs of bipolar conjugate points.

antenna and a notebook included in the Leica GPS Spider software for data logging. The dual-frequency Leica Choke-ring antenna was fully equipped with a Dorne Margolin with weather-protection radome. The groundbased meteorological system uses Paroscientific broadband MET4A sensors, which were installed co-located with the GPS antenna to precisely measure the surface pressure (in bars), air temperature (in degrees Celsius) and relative humidity (in percent). The GPS antenna and MET4A sensors were fixed on the ground in a base pillar with a height of $5.20 \mathrm{~m}$. The meteorology and the GPS systems are integrated; thus, the GPS data in the RINEX folder consisted of observation (".obs), navigation (*.nav) and meteorological data (*.met) files. The GPS receiver at SBA was installed in November 2002 (see the report of Suparta et al. [2008] for more details). The GPS data for SYOG and RESO were downloaded from the GARNER archives at the SOPAC homepage (http:/ / sopac.ucsd.edu).

The geodetic GPS receivers generally collect dualfrequency data at $30 \mathrm{~s}$ intervals. To obtain the absolute TEC and PWV values, the GPS data were converted and checked using the Translate/Edit/Quality Check (TEQC) routine developed by UNAVCO (http:/ / www. u-navco.org). In this work, geometry-free linear combinations of measurements from the same dual-frequency satellite, such as $\left(\Phi_{1}-\Phi_{2}\right)$ or $\left(P_{1}-P_{2}\right)$, were used to estimate the variations in the inter-frequency ionosphere delays. With this approach, the TEC measured from dual-frequency code and phase measurements can be calculated using (1) [e.g., Ephishov et al. 2000, Warnant and Pottiaux 2000, Hofmann-Wellenhof et al. 2001].

$$
\begin{aligned}
& P_{r}^{s}=P_{r}^{s}(L 1)-P_{r}^{s}(L 2) \text { and } \\
& \Phi_{r}^{s}=\Phi_{r}^{s}(L 1)-\Phi_{r}^{s}(L 2)
\end{aligned}
$$

The geometry-free linear combination of dual-frequency code and phase measurements as a function of TEC can be calculated using (1)

$$
\begin{aligned}
& P_{r}^{s}=-0.105 T E C_{r}^{s}+\left(D g_{r}-D g^{s}\right) \text { and } \\
& \Phi_{r}^{s}=-0.552 T E C_{r}^{s}+N_{r}^{s}
\end{aligned}
$$

The ambiguity term can be resolved by combining the geometry-free code with phase measurements for each satellite path using (2)

$P_{r}^{s}-\lambda_{1} \Phi_{r}^{s}=\left(D g_{r}-D g^{s}\right)-\lambda_{1} N_{r}^{s}$

The equivalent vertical TEC (VTEC) can be obtained for each satellite path using (2) and (3)

$$
\begin{aligned}
\operatorname{VTEC}_{r}^{s} & =\mathrm{TEC}_{r}^{s} \cos \chi \text { and } \\
\cos \chi & =\left[1-\frac{\cos ^{2} \theta}{\left(1+h_{m} / R_{E}\right)^{2}}\right]^{1 / 2}
\end{aligned}
$$

where $P_{r}^{s}(L 1)$ and $P_{r}^{s}(L 2)$ are GPS P-code in meters, $\Phi_{r}^{s}(L 1)$ and $\Phi_{r}^{s}(L 2)$ are carrier phase in cycles, $D g_{r}$ and $D g^{s}$ are the receiver and satellite differential group delay, $N_{r}^{s}$ is the ambiguity term in cycles, $\lambda_{1}$ is the wavelength of the frequency $f_{1}$ in meters, $\theta$ and $\chi$ are the elevation angles in degrees at the receiver site and at the ionospheric pierce point (IPP), respectively, and $h_{m}$ is the height at sub-ionospheric points. This height was set to $400 \mathrm{~km}$, approximately corresponding to the altitude of maximum electron density. $R_{E}$ is the radius of the Earth and is taken as 6,378,137 meters. The absolute GPS TEC results are then corrected using satellite and receiver bias values from the nearest GPS stations available from the data center of Bern University, Switzerland. For example, the equivalent GPS station for Scott Base (SBA) is the GPS station at McMurdo (MCM4).

For the lower atmosphere, the PWV total is determined from the GPS signals and the surface meteorological data. The total tropospheric delay in the zenith direction can be formulated as

$Z T D=Z H D+Z W D$ 
where ZTD is the zenith tropospheric delay in the equilibrium state as a function of slant delays and mapping functions. The zenith hydrostatic delay (ZHD) is a delay component caused by the dry gases in the troposphere and the non-dipole component of water vapor refraction. The zenith wet delay (ZWD) is a delay caused solely by the components of the dipole moment and dipole orientation of water refraction. The ZTD in this work was estimated based on the improved Modified Hopfield model, which can be expressed as [Hofmann-Wellenhof et al. 2001, Suparta et al. 2008]

$$
Z T D=10^{-6} N_{j, 0}^{T r o p}\left[\sum_{k=1}^{9} \frac{\alpha_{k, j}}{k} r_{j}^{k}\right]
$$

where

$$
\begin{aligned}
& \alpha_{j, 1}=1 \\
& \alpha_{j, 2}=4 a_{j} \\
& \alpha_{j, 3}=\left(6 a_{j}^{2}+4 b_{j}\right) \\
& \alpha_{j, 4}=4 a_{j}\left(a_{j}^{2}+3 b_{j}\right) \\
& \alpha_{j, 5}=\left(a_{j}^{4}+12 a_{j}^{2} b_{j}+6 b_{j}^{2}\right) \\
& \alpha_{j, 6}=4 a_{j} b_{j}\left(a_{j}^{2}+3 b_{j}\right) \\
& \alpha_{j, 7}=b_{j}^{2}\left(6 a_{j}^{2}+4 b_{j}\right) \\
& \alpha_{j, 8}=4 a_{j} b_{j}^{3} \\
& \alpha_{j, 9}=b_{j}^{4}
\end{aligned}
$$

and

$$
\begin{aligned}
& a_{j}=-\frac{\sin \theta}{h_{j}}, b_{j}=-\frac{\cos ^{2} \theta}{2 h_{j} R_{E}}, \\
& r_{j}=\sqrt{\left(R_{E}+h_{j}\right)^{2}-\left(R_{E} \cos \theta\right)^{2}}-R_{E} \sin \theta
\end{aligned}
$$

where the parameters in the brackets are a solution of the mapping function in the form of a series expansion, $\alpha_{j, k}$ with $k$ denoting the layer. Subscript $j$ is replaced with $h$ for the hydrostatic component, and subscript $j$ is replaced by $w$ for the wet component. In (7), $h_{j}$ (in meters) represents $h_{h}\left(h_{h}=40136+148.72 T\right)$ and $h_{w}$ (set to $11 \mathrm{~km}$ ), which are the effective heights for the hydrostatic and wet components, respectively, and $r_{j}$ is the solution model of the integral that covers the hydrostatic and wet portions of tropospheric delay. $N_{j, 0}^{\text {Trop }}$ is the total refractivity at the surface of the Earth.

The ZHD is calculated using the Saastamoinen model [Saastamoinen 1972]. ZHD uses the surface pressure $(P)$ measurements and a correction factor to correct the local gravitational acceleration at the center of mass of the atmospheric column, which can be expressed as follows and has a value close to unity:

$$
Z H D=\frac{(2.2768 \pm 0.0024) P}{(1-0.00266 \cos (2 \lambda)-0.00028 h)}
$$

where $\lambda$ is the station latitude (in degrees) and $h$ is the height of the site above the ellipsoid (in km) as measured by the GPS receiver.

In this work, the hydrostatic Vienna Mapping Function (VMF1) $m_{h}(\theta)$ is employed to reduce the dependence of the zenith delay (ZTD) on the satellite elevation angle. This mapping function uses the European Centre for Medium-Range Weather Forecasts (ECMWF) instead of the Numerical Weather Models (NWMs) because of its greater sensitivity and suitability for Polar Regions and is written as

$$
\begin{aligned}
& m_{h}(\theta)=m(\theta)+\Delta m(\theta)= \\
& =\frac{1+(a /(1+b /(1+c)))}{\sin \theta+(a / \sin \theta+(b / \sin \theta+c))}+ \\
& +\left[\frac{1}{\sin \theta}-f\left(\theta, a_{h t}, b_{h t}, c_{h t}\right)\right] h
\end{aligned}
$$

where the coefficients $a, b$ and $c$ are interpolated from the latitude of the GPS site and take seasonal variations into account. Boehm et al. [2006] has updated the " $\mathrm{b}$ " and " $\mathrm{c}$ " coefficients of the Marini continued fraction form in (9). Here, $f\left(\theta, \alpha_{h t}, b_{h t}, c_{h t}\right)$ represents the three-term continued fraction in the Marini mapping function:

$$
\begin{aligned}
& f\left(\theta, a_{h t}, b_{h t}, c_{h t}\right)= \\
& =\frac{1+\left(a_{h t} /\left(1+b_{h t} /\left(1+c_{h t}\right)\right)\right)}{\sin \theta+\left(\sin \theta+a_{h t} /\left(\sin \theta+b_{h t} /\left(\sin \theta+b_{h t}\right)\right)\right)}
\end{aligned}
$$

The coefficients $a_{h t}=2.53 \times 10^{-5}, b_{h t}=5.49 \times 10^{-3}$ and $c_{h t}=1.14 \times 10^{-3}$ were determined by a least-squares fit to the height corrections at nine elevation angles.

When ZTD was mapped onto the satellite elevation angle using the VMF1, the ZWD was then calculated by subtracting the ZHD from the ZTD (see Equation 5). The PWV can now be calculated as proposed by Bevis et al. [1994]

$P W V=\pi\left(T_{m}\right) Z W D$

where the dimensionless $\pi\left(T_{m}\right)$ parameter is a conversion factor that varies with the summation on the local climate (e.g., location, elevation, season and weather) and depends on a weighted mean temperature $\left(T_{m}\right)$, as given by

$\pi\left(T_{m}\right)=\left[\rho_{l w} R_{v}\left(k_{2}^{\prime}+k_{3} / T_{m}\right)\right]^{-1} 10^{6}$

where $\rho_{l w}$ and $R_{v}$ are the density of liquid water (1000 $\mathrm{kg} \mathrm{m}^{-3}$ ) and the specific gas constant for water vapor $\left(461.5184 \mathrm{~J} \mathrm{~mol}^{-1} \mathrm{~K}^{-1}\right.$ ), respectively. According to (12), $k_{2}^{\prime}$ and $k_{3}$ are the refraction constants: $k_{2}^{\prime}=(22.1 \pm 2.2)$ 
$\mathrm{Kmb}^{-1}$ and $k_{3}=(3.739 \pm 0.012) \times 10^{5} \mathrm{~K}^{2} \mathrm{mb}^{-1}$. The mean temperature $T_{m}$ is estimated linearly [Bevis et al. 1994]:

$T_{m}=70.2+0.72 T_{K}$

where $T_{K}$ is the surface air temperature in Kelvin. The GPS PWV has been compared with the PWV from Radiosonde [Suparta 2010], and it was found that the Radiosonde PWV in the Polar Regions is not significantly different (less than 2\%) from the mid-latitude region. Thus, $T_{m}$ is calculated from the surface temperature $(T)$ measured at a particular site. The $\pi\left(T_{m}\right)$ value for Polar Regions ranges between $0.14-0.15$, which is lower by approximately $3 \%$ than the value in the mid-latitude region.

Assuming that all the instrumental biases can be isolated through the use of differencing techniques and by simultaneously reducing the satellite orbit errors, the remaining errors are expected to be only caused by ionospheric and tropospheric influences. In addition to the instrumental effects, the removal of the ionospheric delay effects from the GPS processing is required to determine the total ZTD. A Matlab program suite, namely, the tropospheric water vapor program (TroWav), was developed to process and analyze all of the above parameters. De-

(a) Vernal Equinox (VE)

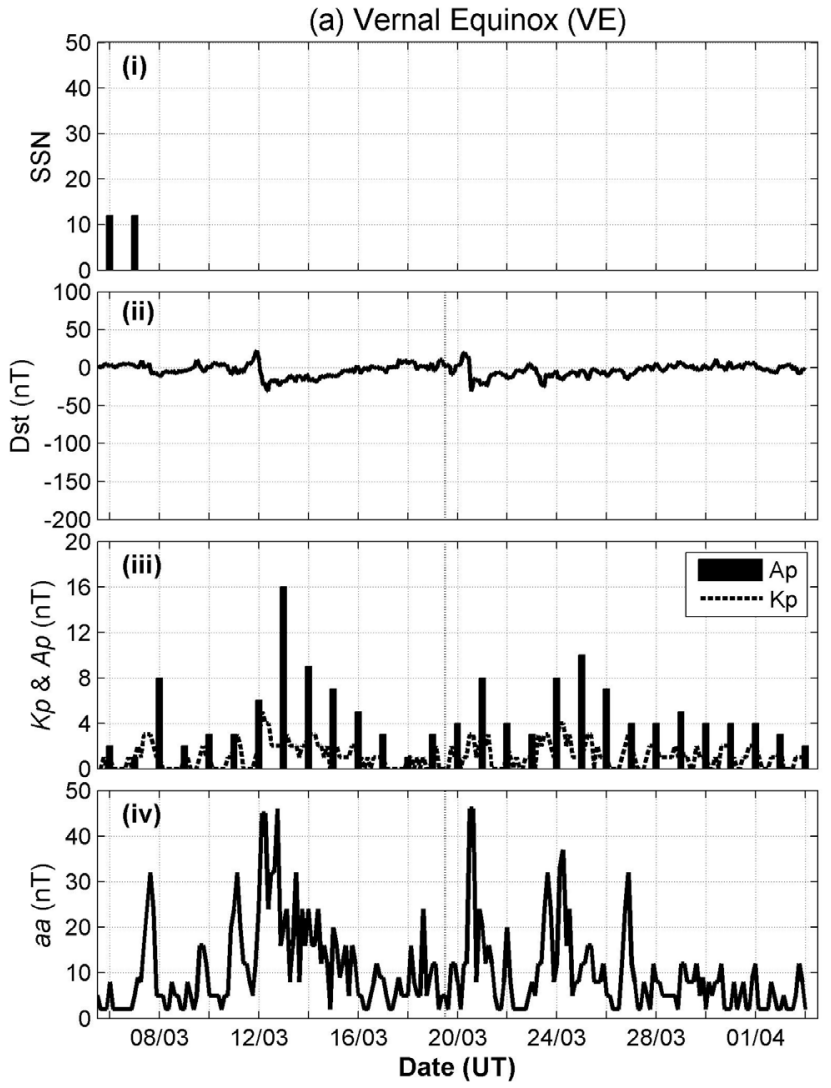

tailed algorithms for TroWav used in this work can be found in Suparta et al. [2008] and Suparta [2010]. The GPS TEC measurements at all stations were collected at $30 \mathrm{~s}$ intervals. The GPS PWV results for all stations were calculated following the interval in the meteorological data. Thus, the PWV products for HUSA, SBA, RESO and SYOG were generated with 1-min, 10-min, $1 \mathrm{~h}$ and $3 \mathrm{~h}$ intervals, respectively. To analyze the equinoxes at all stations, the data were averaged with interval of $15 \mathrm{~min}$ for GPS TEC and $3 \mathrm{~h}$ for GPS PWV. Approximately one month (two weeks before and after the equinox onsets) of data for the TEC and the PWV at two pairs of conjugate stations, as well as solar activity, were analyzed. The analysis consisted of correlating the TEC and PWV measurements. This correlation analysis was selected as the best method of determining the association between two unknown variables.

\section{Results and discussion}

\subsection{Solar activity during the 2009 equinoxes}

Figure 2 shows the solar and geomagnetic activity during the 2009 equinoxes for both VE and AE. The sunspot number (SSN) on the top panel was recorded

(b) Autumnal Equinox (AE)
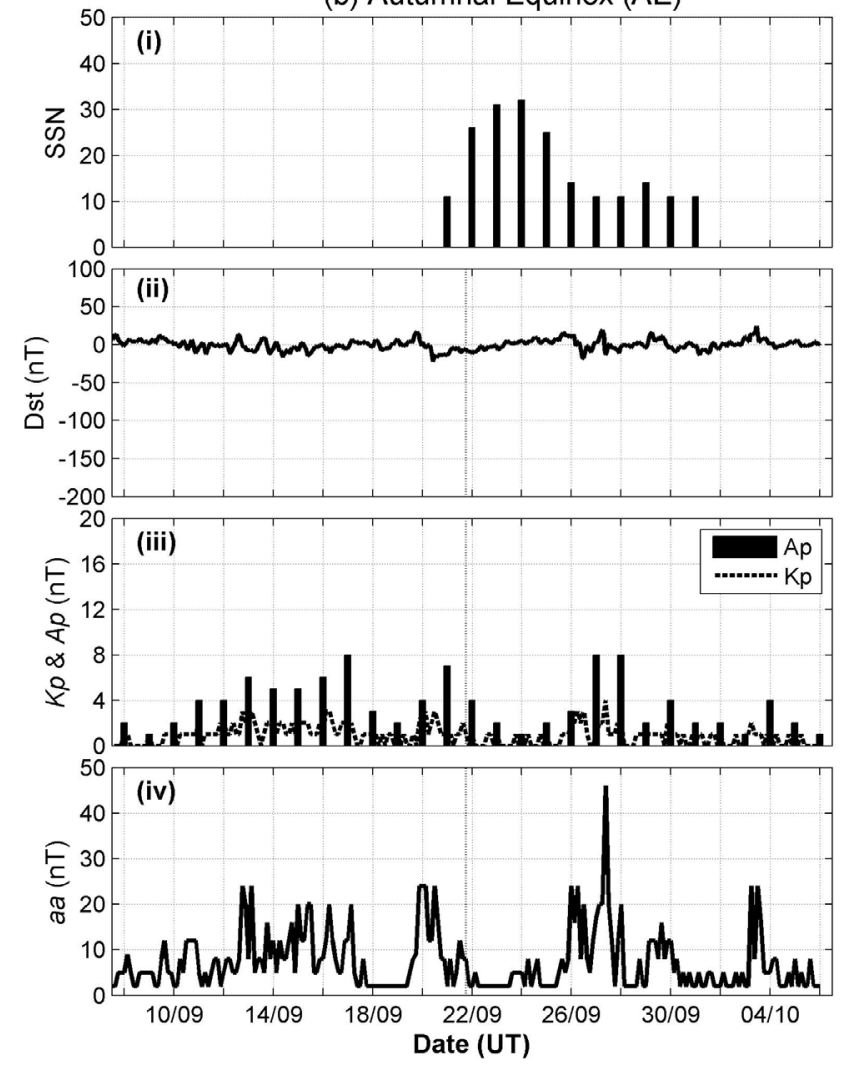

Figure 2. Solar-geomagnetic activity during the 2009 equinox periods. The vertical dashed lines denote the vernal equinox (VE) onset on March 20 at 11:44 UT and the autumnal equinox (AE) onset on September 22 at 21:18 UT. The date marked on the figure is in $\mathrm{dd} / \mathrm{mm}$ format. The sunspot number (SSN), the 3-hour Kp and the daily Ap indices were obtained from the NOAA/SEC website (http://www.swpc. noaa.gov), and hourly Dst (nT units) was obtained from the World Data Center-C2 for geomagnetism, Kyoto (http:/ / wdc.kugi.kyoto-u.ac.jp). 
as a maximum of 12 before VE and 32 after AE. The geomagnetic conditions shown in the second and third panels are categorized as low activity with four minorto-unsettled storms ( $3 \mathrm{~h} \mathrm{Kp}>4,8<A p<16$ ) and one storm with a minimum disturbance storm time (Dst) of -31 $\mathrm{nT}$ that occurred on March 12. The Dst is an index that is commonly used to identify and quantify magnetic storms as a reflection of the level of magnetospheric energy input to the upper atmosphere based on ground measurements. The maximum 3-h value of the $a a$ index of $46 \mathrm{nT}$ (bottom of Figure 2) was recorded for the VE and $\mathrm{AE}$ periods that occurred 8 days before and 5 days after the onsets of $\operatorname{VE}(A p=16 \mathrm{nT})$ and $\mathrm{AE}(A p=8 \mathrm{nT})$, respectively. Similar to the $A p$ and $K p$ indices, the $a a$ index was used as a proxy for solar irradiance linking to the Earth's climate through terrestrial surface temperature records [Cliver et al. 1998]. At the onset of VE on March 20, Ap and $a a$ indices were recorded at low values of 4 and $8 \mathrm{nT}$, respectively, with a Dst of $2 \mathrm{nT}$. Note that increases in the geomagnetic activity were observed on March 12 and 21, perhaps due to the topology of the geomagnetic field at ground level. It is interesting to note that at the onset of AE on September 22, all recorded values of geomagnetic activity were low, which is similar to the observations at the onset of VE. Subsequently, SSN reached a maxi-

(a) VE
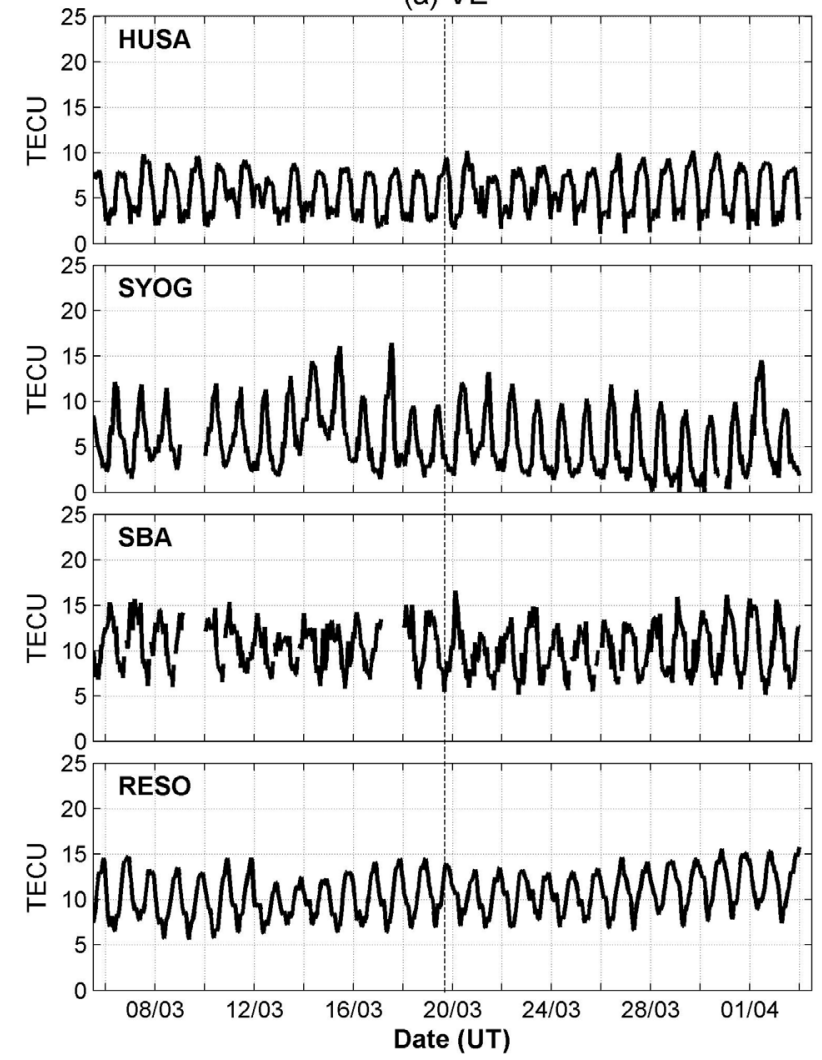

mum of 32 on September 24, followed by increases of geomagnetic activity between September 27 and 28. Overall, low solar activity was observed during these equinoxes, and their conditions can be categorized as quiet.

\subsection{TEC and PWV observations during the 2009} equinoxes

In the following section, the analyses of TEC and PWV during the 2009 equinoxes will be presented according to (1) variation in the two weeks before and after the equinoxes and (2) the onset day of equinox.

\subsubsection{TEC response}

Figure 3 shows the one-hour average of TEC variation for two weeks before and after the equinoxes. The TEC exhibits a diurnal pattern with different oscillatory patterns at different stations. For VE, HUSA-RESO exhibited a stable fluctuation, while SYOG and SBA exhibited fluctuations one week before the onset of VE and then increased trend. In certain periods, SBA was found to lack GPS data for VE and AE, and thus, the response of the SBA-RESO pair will be approximated. The TEC variation at the onset of $\mathrm{VE}$ and $\mathrm{AE}$ exhibited opposite patterns in the two hemispheres for both station pairs. (b) $\mathrm{AE}$

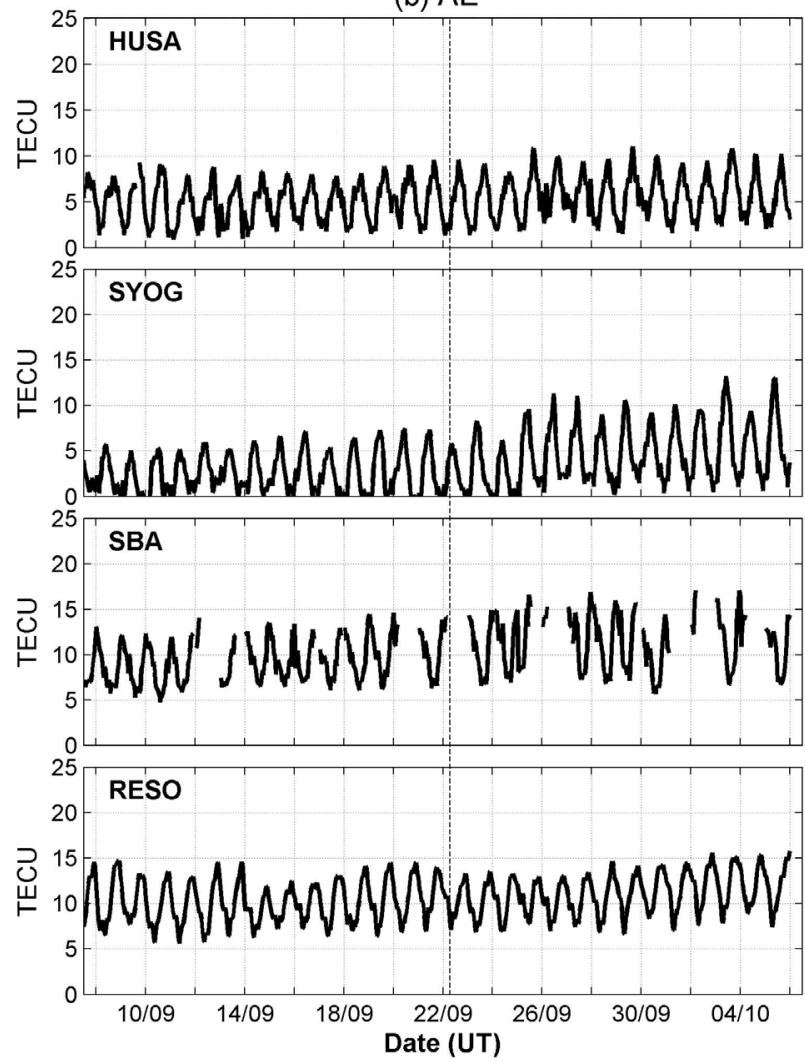

Figure 3. The TEC variation at both conjugate pairs for a 14-day period before and after the (a) vernal equinox (VE) and (b) autumnal equinox (AE), respectively. The vertical dashed line indicates the onset. 
One pattern observed at the paired stations is that of solar influence: the $\mathrm{SH}$ received less light and exhibited reduced TEC, while the NH received more light and exhibited increased TEC. There is not a clear signature of interhemispheric influences (either similarity or asymmetry), particularly during VE. Thus, spatial TEC variation during equinoxes seems influenced by seasonal dependencies.

To compare the TEC variation during the onset of equinox, 2 hours of TEC map structure during VE (March 20) and AE (September 22) are presented in Figure 4. The geographic longitudes (GLon) depicted in the figure are assumed to be close to the values for HUSA $\left(-20.0^{\circ}\right)$, SYOG $\left(40.0^{\circ}\right)$, RESO $\left(-95.0^{\circ}\right)$ and SBA $\left(170.0^{\circ}\right)$. The values are approximate because NASA's crustal dynamics data interchange system (CDDIS) only provides TEC values at 5 degree intervals. For both VE and $\mathrm{AE}$ at all stations, HUSA-SYOG (at the top two panels in Figure 4) exhibited higher TEC during the mid-day, whereas SBA-RESO (at the bottom two panels in Figure 4) exhibited lower TEC in the mid-night. The stations in the NH (HUSA and RESO) and in the SH (SBA and SYOG) are arranged in a rough triangle, differentiated only slightly by the shape and distribution of TEC. Only SBA (GLon: $170.0^{\circ}$ ) has a different distribution between $\mathrm{VE}$ and $\mathrm{AE}$, in which the TEC duration during $\mathrm{AE}$ in the morning is double than that of VE. Comparing to Figure $4 \mathrm{~b}$, the slight TEC movement can be clearly observed, with a similar pattern following the seasonal trend.

With regard to the onset of $\mathrm{VE}$ and $\mathrm{AE}$, Figure 5 shows the TEC map for VE between 10:00 UT and 12:00 UT and for AE from 20:00 UT until 22:00 UT. At 10:00 UT on March 20, the TEC exhibited higher values between $\pm 15^{\circ}$ latitude and $20-90^{\circ}$ longitude. The TEC then moved toward the equator (reduced) at 22:00 UT.
At 20:00 UT on September 22, the TEC exhibited higher values between $-10^{\circ}$ and $+15^{\circ}$ latitude and $-30^{\circ}$ and $-120^{\circ}$ longitude. The TEC then moved toward the pole (enhanced) at 22:00 UT. One can conclude from the TEC movement during the onset of VE and $\mathrm{AE}$ that the seasonal cycles in the polar and temperate zones of one hemisphere are the opposite of those in the other hemisphere. When it is summer (more sunlight received) in the $\mathrm{NH}$, it is winter (less sunlight received) in the $\mathrm{SH}$, and vice versa. From the perspective of a given geographical longitude (GLon), the TEC exhibits positive (higher) values during VE and negative (lower) values during AE, and vice versa.

\subsubsection{PWV response}

Figure 6 shows the hourly average temporal PWV variation for 14 days before and after both $\mathrm{VE}$ and $\mathrm{AE}$ at bipolar conjugate points. In addition to the validation of the GPS PWV, daily averages of PWV from Radiosonde (RS) are presented. The RS PWV data were taken from the Wyoming University website. Note that the equivalent to the GPS at HUSA is the RS at BIKF (station number $(\mathrm{S} / \mathrm{N})$ : 4018 , location: $63.96^{\circ} \mathrm{N}, 22.60^{\circ} \mathrm{W}$ at an elevation of $54.0 \mathrm{~m}$ ); the equivalent to the GPS at SBA is the RS at McMurdo (S/N: 89664 , location: $77.85^{\circ} \mathrm{S}$, $166.66^{\circ} \mathrm{E}$ at an elevation of $24.0 \mathrm{~m}$ ); the equivalent to the RS at RESO is the RS at YRB ( $/ \mathrm{N}$ : 71924, location: $74.70^{\circ} \mathrm{N}, 94.96^{\circ} \mathrm{W}$ at an elevation of $40.0 \mathrm{~m}$ ); and the equivalent for SYOG is 89532 (location: $69.00^{\circ} \mathrm{S}, 39.58^{\circ} \mathrm{E}$ at an elevation of $21.0 \mathrm{~m}$ ). Considering the differences between GPS and RS position, only HUSA and KIBF are separated by a relatively long distance $(\sim 100 \mathrm{~km})$.

Across all stations, the PWV values from GPS and RS exhibited a positive linear trend and agreed very (a) VE
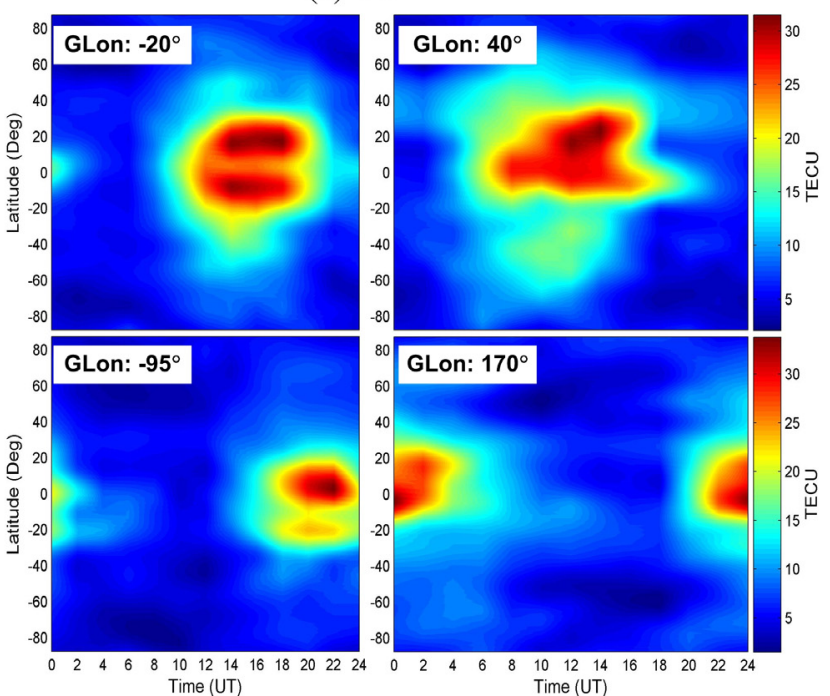

(b) $\mathrm{AE}$

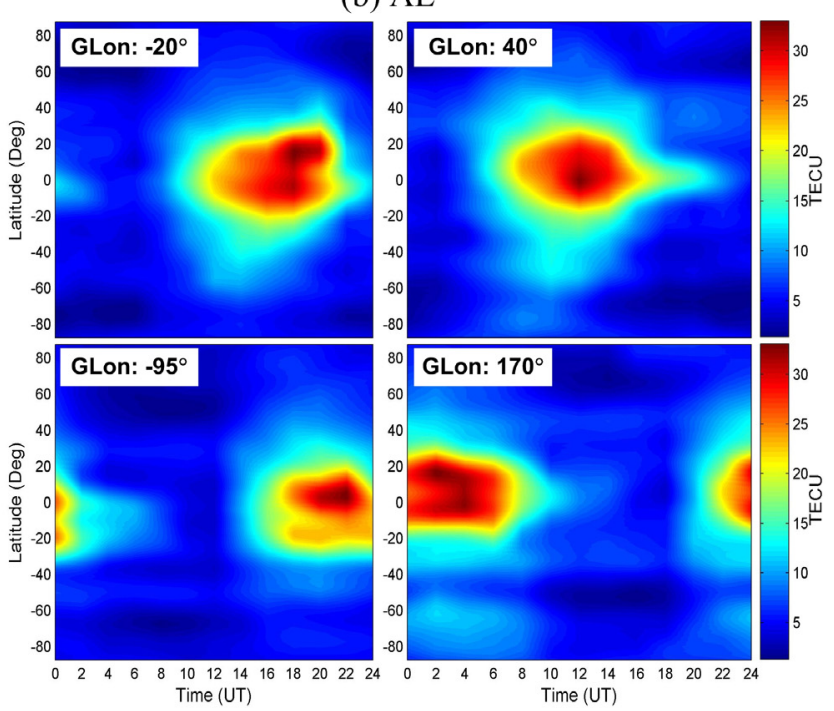

Figure 4. TEC maps for each station with geographical longitude (GLon) during the onset day of (a) VE (March 20) and (b) AE (September 22). 


\section{(a) VE}

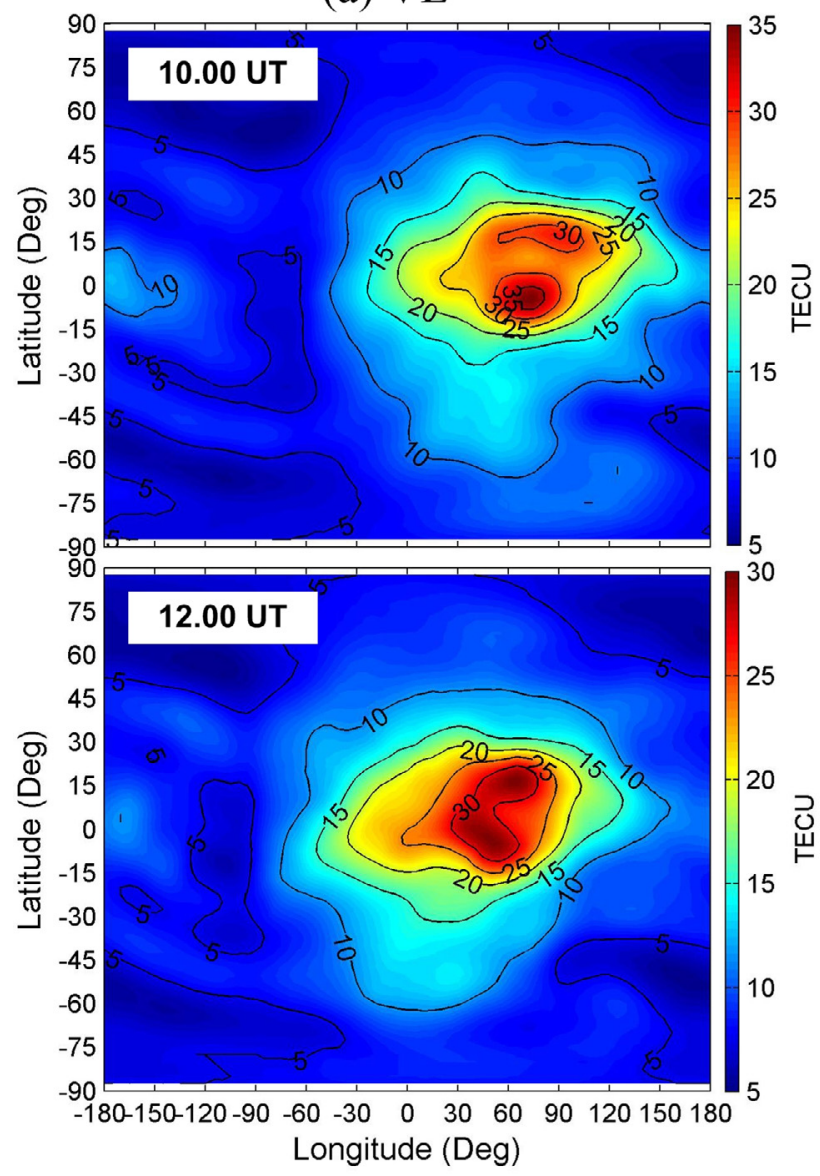

Figure 5. TEC maps between the onset of (a) AE and (b) VE.

(a) VE

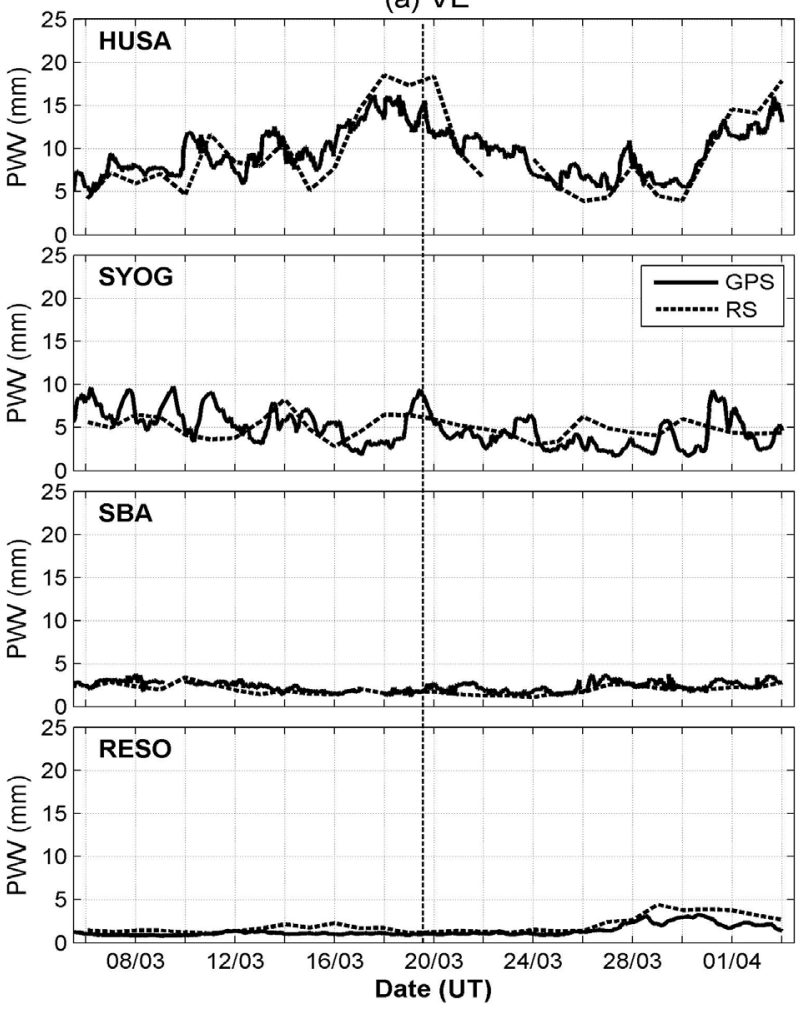

(b) $\mathrm{AE}$

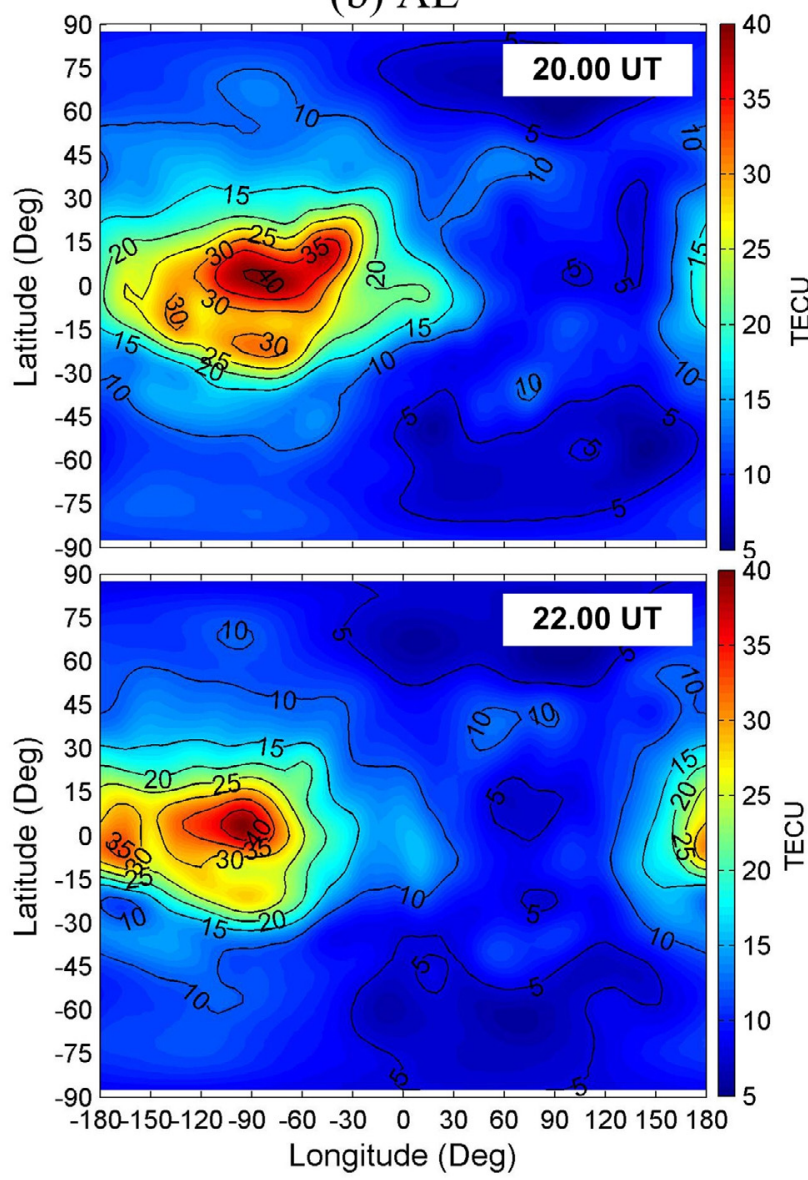

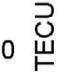

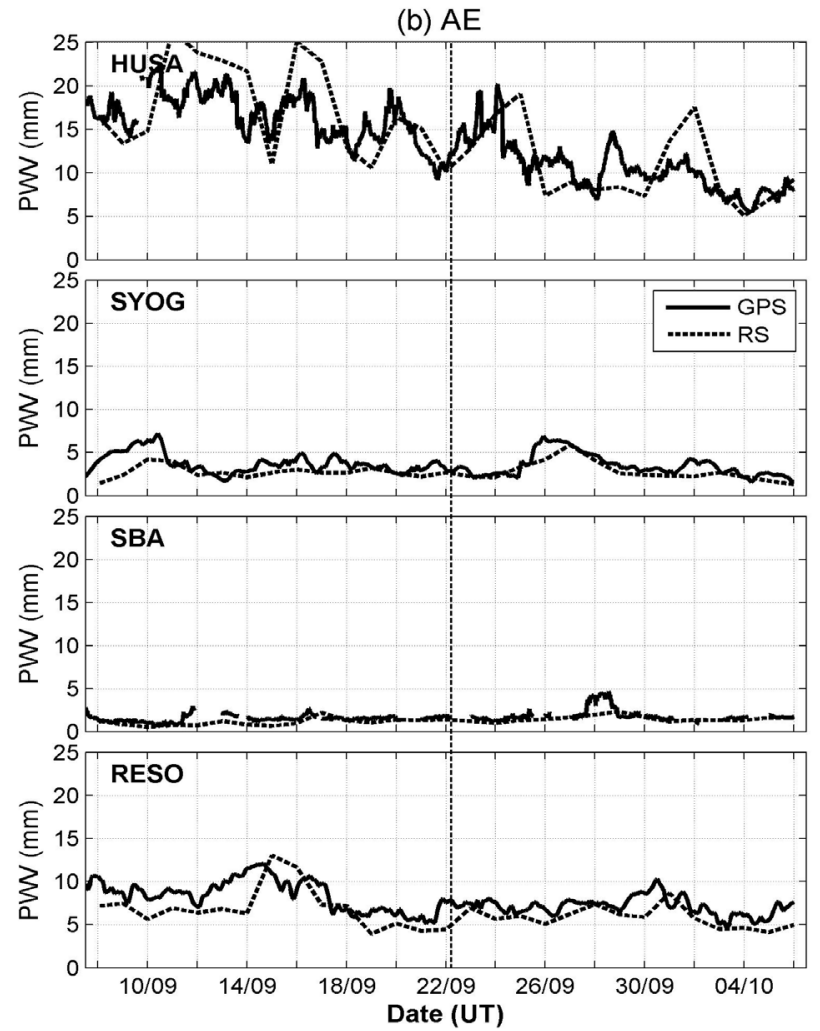

Figure 6. A comparison of PWV between the GPS and RS measurements for two weeks before and after the onset day of (a) VE and (b) AE. 
well. For the HUSA station, the PWV values were higher than for other stations. The conjugate pair of HUSA-SYOG in Figure 6a shows more fluctuation than the pair of SBA-RESO. On the VE onset day, the pair of HUSA-SYOG exhibited a PWV value approximately 6.4 $\mathrm{mm}$ higher than their average value $(\sim 7.2 \mathrm{~mm})$. For $\mathrm{AE}$ in Figure $6 \mathrm{~b}$, the PWV at HUSA exhibited a decreasing trend, whereas the other three stations exhibited low fluctuations. However, there are two high peaks of PWV at each station, which alternate every two days and oscillate when the angle approaches $30^{\circ}$ (for example, on September 24 at HUSA, September 26 at SYOG, September 28 at SBA and September 31 at RESO). The occurrence of these oscillatory peaks before and after the AE onset day is a unique phenomenon caused by the daily variation of the station. Convincingly, the PWV value for the SH stations was one-third lower than for the stations in the NH. The high PWV value observed in the $\mathrm{NH}$ is possibly due to the Arctic surface being more explored than the SH. The PWV can clearly be seen to increase at the onset of VE for HUSA-SYOG, whereas the opposite trend is shown for the AE onset. In general, the PWV response in the conjugate pairs for both $\mathrm{VE}$ and $\mathrm{AE}$ will be stronger when the sun is more exposed.

Figure 7 shows the spatial variation of PWV with latitude: $45^{\circ}$ to $90^{\circ} \mathrm{N} / \mathrm{S}$ and longitude $0^{\circ}$ to $100^{\circ} \mathrm{W}$ $(\mathrm{NH})$ and $30^{\circ}$ to $180^{\circ} \mathrm{E}(\mathrm{SH})$ during the $\mathrm{VE}$ and $\mathrm{AE}$ at four selected stations. Each station in the figure is marked by a solid red circle. The PWV map (in mm) is generated based on 4-times daily observations at the surface level from the NCEP/NCAR Reanalysis 1. From both figures, the PWV at RESO and SBA during VE is estimated to be $\sim 2 \mathrm{~mm}$ (shown by green color). However, the PWV at HUSA is estimated to be double $(\sim 6 \mathrm{~mm})$ that of the PWV at SYOG. The high value of PWV at HUSA is consistent with Figure 6a. For the case of AE, SBA-RESO and HUSA-SYOG showed anticorrelation, whereas PWV was similar in both hemispheres. The low PWV value during AE in the $\mathrm{NH}$ station is due to the seasonal dependence. This seasonal phenomenon is a result of the Earth's axis being tilted to relative to its orbital plane (the elliptical orbit of Earth). When the center of the Sun is above the horizon, its lower edge is visible. In other words, the Arctic region experiences a high density of incident rays, while the other side (the Antarctic region) experiences a low density of incident rays. Hence, the seasonal cycle in the polar regions of one hemisphere would be opposite to that of the polar regions of the other hemisphere. This condition greatly affects the PWV movement between the poles.

\subsubsection{Associations between the upper and lower} atmosphere

The associations between the upper and lower levels of the atmosphere evident from the TEC and PWV observations (shown in Figures 3 and 6) at the conjugate stations are presented in Figure 8. The TEC and PWV relationship is characterized by a correlation coefficient $(r)$, which is calculated at the $99 \%$ confidence level for each station and presented in the associated figures. The (a) VE

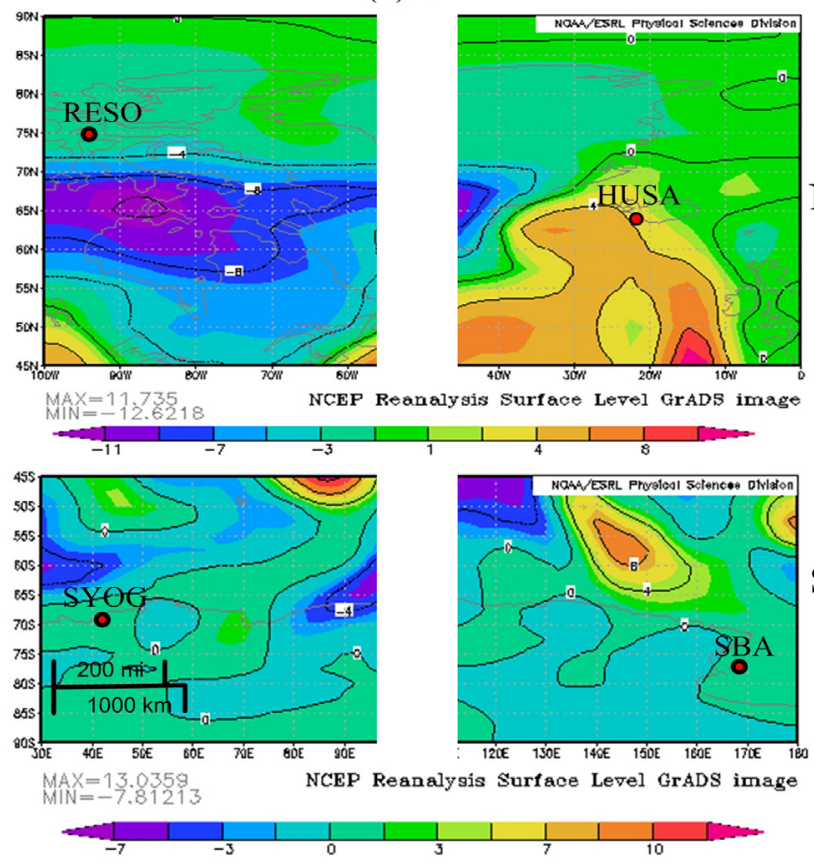

(b) $\mathrm{AE}$
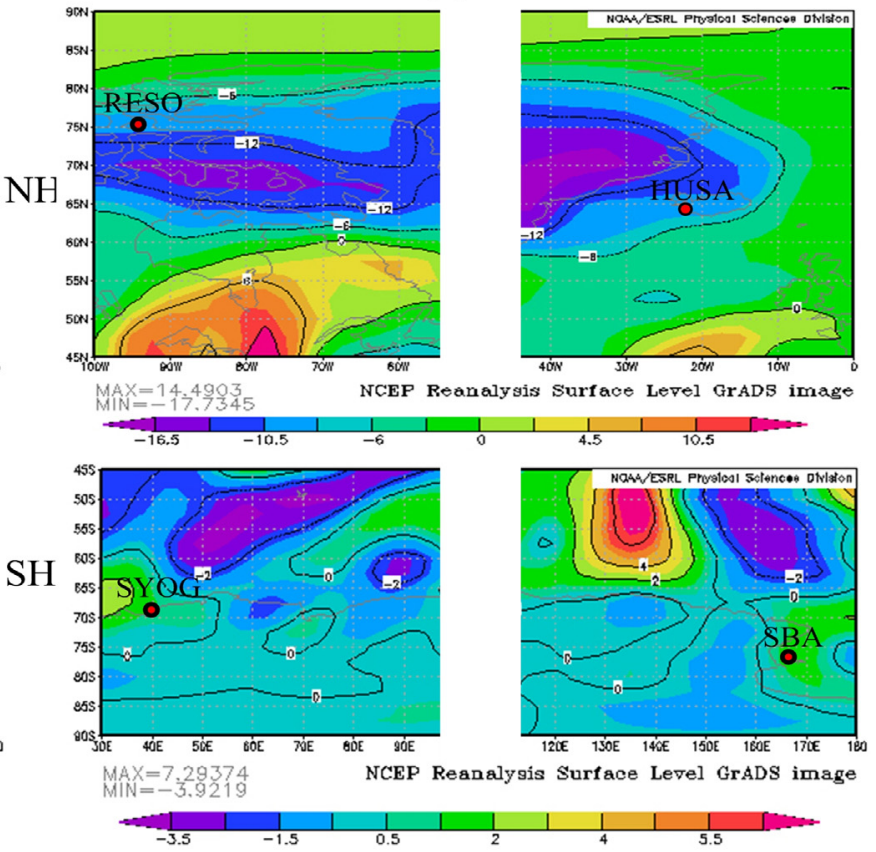

Figure 7. Spatial PWV variation for the onset day of (a) VE (March 20, 2009) and (b) AE (September 22, 2009) courtesy of NOAA. 

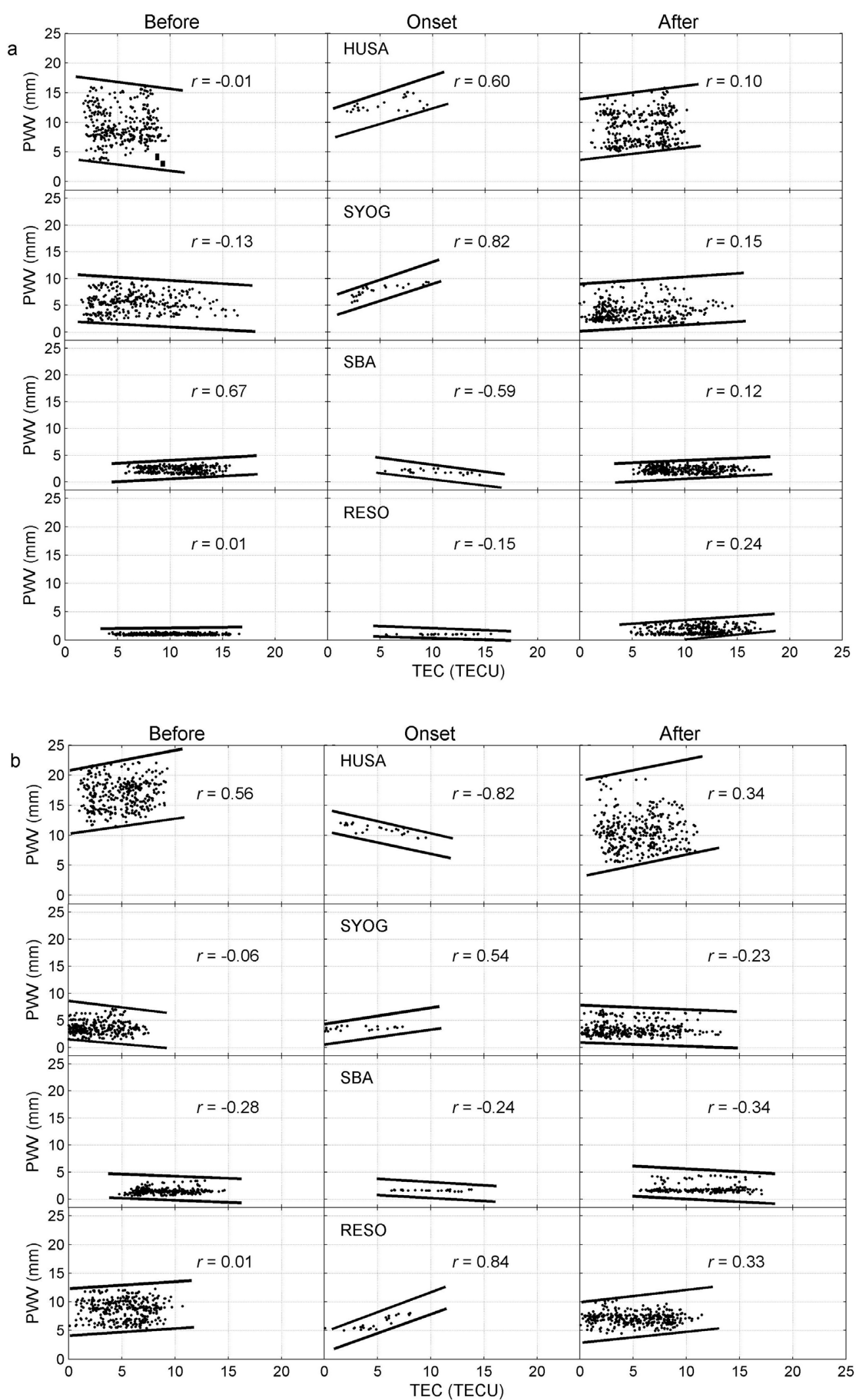

Figure 8. Association between TEC and PWV variations at bipolar conjugate stations for (a) VE and (b) AE before, during the onset day and after the equinoxes.

autocorrelation in the data series was taken into account when establishing the statistical significance. During the VE, the bipolar stations exhibited complicated trends with ups and downs for each station. For example, the pairs of HUSA-SYOG and SBA-RESO show an opposite trend before the VE onset day, while after VE, all stations tend to increase. However, it should be noted that there is no correlation for before and after the VE onset day 
across all of the stations. At the onset day of VE, a good TEC and PWV relationship was found at all stations: the pair of HUSA-SYOG shows an upward trend, whereas SBA-RESO showed the opposite.

Similar plots are shown for the AE. Before the onset day, the stations' trends are similar to those recorded for VE. The figure also shows that there is no relationship between TEC and PWV for all stations. However, anti-correlation between the stations in the $\mathrm{NH}$ and $\mathrm{SH}$ was observed after the AE. At the onset day of AE, HUSA-SYOG and SBA-RESO showed anti-correlation, which is dissimilar to the onset day of VE. Generally speaking, the correlations between TEC and PWV during the onset day (equinox) exhibit opposite trends for the HUSA-SYOG and SBA-RESO pairs. This is due to the equinox signal that is observed moving from the beginning of spring in the $\mathrm{NH}$ and autumn in the $\mathrm{SH}$ when the sun crosses the celestial equator going from south to north. Therefore, the Antarctic station receives the sun rays before the station in the NH. As a result, the explanation is the same as in Section 3.2.2, where the high and low values of the TEC and PWV are greatly dependent on the seasonal difference between the hemispheres. Thus, the association between the upper and the lower levels of atmosphere through behavior of both TEC and PWV respond to the sun at bipolar conjugate pairs during a low solar activity is observed complexes that physically difficult to explain, although good correlation was observed during the onset day for each station.

\section{Summary and conclusion}

The characterization of the interhemispheric conjugate effects in terms of TEC and PWV variations during equinoxes has been conducted at pair stations: HUSA-SYOG and SBA-RESO in the Polar Regions. Analyses for before, after and the onset day of both VE and AE during 2009 are summarized as follows.

First, the TEC and PWV variations before and after the equinox between the hemispheres were both associated with normal day-to-day variability of the middleto-high latitude ionosphere (with some triggering disturbed conditions, as evident in Figure 2) and to normal weather variability, respectively. However, both parameters showed fluctuations and diversity, especially PWV, which has an indistinct pattern. The difference in TEC peaks can be expected due to daily variations between the stations. The PWV variation does not closely follow the TEC patterns, which indicates that the interface between the troposphere and the bottom of the ionized atmosphere is complex. HUSA station recorded a higher amount of PWV compared to RESO due to its location in the Arctic Circle, which passes through the
Arctic Ocean. Second, the relationship between TEC and PWV for before and after both the VE and $\mathrm{AE}$ showed a similar lack of correlation. At the onset day of the equinoxes, the quantity in the $\mathrm{SH}$ station was anticorrelated with that of the station in the NH. Overall, the conjugate pairs of stations show a consistent correlation during the AE, but the case of HUSA-SYOG during the VE is unusual. In other words, a high correlation was observed to follow a seasonal pattern in each hemisphere; during VE, a strong correlation was found in Antarctica $\left(r_{\text {SBA-SYOG }}=0.71\right)$ and a moderate correlation was found in the Arctic $\left(r_{\text {HUSA-RESO }}=0.53\right)$, and vice versa for the $\mathrm{AE}\left(r_{\text {HUSA-RESO }}=0.83\right.$ and $\left.r_{\text {SBA-SYOG }}=0.51\right)$. These findings clearly demonstrated that the hemisphere experiences summer at perihelion and winter at aphelion, implying that the TEC value was clearly influenced by solar activity. Third, the intensity of the solar radiation incident on the lower atmosphere over the Antarctic region and its weakness at the conjugate dayside station are noticeable and correspond to the presence of seasonal effects. Between the hemispheres, both quantities are clearly shown to exhibit opposite patterns (asymmetries).

In conclusion, the relationship between TEC and PWV during the equinoxes within the solar minimum condition is expected to be asymmetrical. Asymmetries are hemisphere-dependent, and higher TEC values can be recorded during the $\mathrm{AE}$ and $\mathrm{VE}$ for the $\mathrm{SH}$ and $\mathrm{NH}$, respectively. However, it is difficult to characterize the PWV response at the conjugate points because the interhemispheric effects are more strongly affected by the upper atmosphere (i.e., TEC variation). The TEC effects on water vapor movement are expected to vary because of the different effects on the propagation media. Strong geophysical disturbances or extreme atmospheric events can be proposed for further comprehensive studies aimed at better understanding the coupling process between the upper and lower levels of the atmosphere. In addition, ancillary data from different sources are needed to support the interpretation of the GPS-based measurements.

Acknowledgements. This work was supported by the Ministry of Higher Education Malaysia (MOHE) under grant UKMLL-07-FRGS0211-2010. The author acknowledges the National Institute of Polar Research (NIPR) Japan and Science Institute of University of Iceland (SIUI) for the collaboration, the Scripps Orbit and Permanent Array Center (SOPAC) for archived GPS data, NASA's crustal dynamics data interchange system (CDDIS) for TEC map data, the National Oceanic and Atmospheric Administration (NOAA) for archiving the PWV map data and Wyoming University for PWV Radiosonde data. The author would like to express his gratitude to Snorri Johannesson for maintaining the GPS system in Iceland during the campaign and give special thanks to Faizatul Noor Abu Bakar and Fadzlina Aini Mohd Lehan for contributing to the data processing. 


\section{References}

Bevis, M., S. Businger and S.R. Chiswell (1994). GPS meteorology: Mapping zenith wet delays onto precipitable water, J. Appl. Meteorol., 33, 379-386.

Boehm, J., B. Werl and H. Schuh (2006). Troposphere mapping functions for GPS and very long baseline interferometry from European Centre for MediumRange Weather Forecasts operational analysis data, J. Geophys. Res., 111, B02406, doi:10.1029/2005JB0 03629.

Businger, S., S.R. Chiswell, M. Bevis, J. Duan, R.A. Anthes, C. Rocken, R.H. Ware, M. Exner, T. van Hove and F.S. Solheim (1996). The promise of GPS in atmospheric monitoring, Bull. Amer. Meteorol. Soc., 77, 5-18.

Cliver, E.W., V. Boriakoff and J. Feynman (1998). Solar variability and climate change: geomagnetic and aa index and global surface temperature, Geophys. Res. Lett., 25, 1035-1038.

Coco, D. (1991). GPS satellites of opportunity for ionospheric monitoring, GPS World, 47-50.

Davies, K., and G. K. Hartmann (1997). Studying the ionosphere with the Global Positioning System, Radio Sci., 32, 1696-1703.

Dragt, A.J. (1965). Trapped orbits in a magnetic dipole field, Rev. Geophys., 3, 255-298, doi:10.1029/RG003 i002p00255.

Ephishov, I.I., L. W.Baran, I.I. Shagimuratov and G.A. Yakimova (2000). Comparison of total electron content obtained from GPS with IRI, Phys. Chem. Earth, 25, 339-342.

Gregorius, T.L.H., and G. Blewitt (1999). Modeling weather fronts to improve GPS heights: A new tool for GPS meteorology? J. Geophys. Res. B: Solid Earth, 104, 15261-15279.

Hofmann-Wellenhof, B., H. Lichtenegger and J. Collins (2001). Global Positioning System: Theory and Practice. Springer Verlag: 5th revised edition, Australia: Springer-Verlag Wien New York.

Klobuchar, J.A. (1996). Ionospheric effects on GPS in Global Positioning System: Theory and Applications, Chapter 12, Parkinson, B. W. and Spilker, J. J. Jr., American Institute of Aeronautics and Astronautics, Washington.

Liu, L., M. He, X. Yue, B. Ning, and W. Wan (2010). Ionosphere around equinoxes during low solar activity, J. Geophys. Res., 115, A09307, doi:10.1029/2010JA0 15318.

Liu, L.B., W.X. Wan, Y.D. Chen and H.J. Le (2011). Solar activity effects of the ionosphere: A brief review, Chinese Sci. Bull., 56, 1202-1211, doi: 10. 1007/s11434010-4226-9.

Perrone, L., and G.D. Franceschi (1998). Solar, ionos- pheric and geomagnetic indices, Annali di Geofesica, 41, 843-855.

Rocken, C., T.V. Hove and R. Ware (1997). Near realtime GPS sensing of atmospheric water vapour, Geophys. Res. Lett., 24, 3221-3224.

Saastamoinen, J. (1972). Introduction to practical computation of astronomical refraction. Bull. Geod., 106, 383-397.

Sato, N., T. Nagaoka, K. Hashimoto and T. Saemundsson (1998). Conjugacy of isolated auroral arcs and non-conjugate auroral break-ups, J. Geophys. Res., 103, 11641-11652.

Seeber, G. (1993). Satellite geodesy, foundations, methods and applications, Walter de Gruyter, Berlin.

Suparta, W., Z.A. Abdul Rashid, M.A. Mohd Ali, B. Yatim and J.G. Fraser (2008). Observations of Antarctic precipitable water vapour and its response to the solar activity based on GPS sensing, J. Atmos. SolTerr. Phys., 70, 1419-1447.

Suparta, W., M. Abdullah, M.A. Mohd Ali, B. Yatim, N. Sato, A. Kadokura, G. Bjornsson and G.J. Fraser (2009). Solar-terrestrial observations at bipolar conjugate points using global positioning system, In: Proceeding International Conference on Instrumentation, Communications, Information Technology and Biomedical Engineering (ICICI-BME), 454-458; http: / / dx.org/ 10.1109/ICICI-BME.2009.5417302.

Suparta, W. (2010). Using a global positioning system to estimate precipitable water vapor in Antarctica, Polar Geog., 33, 63-79.

Wanninger, L. (1993). Effects of the Equatorial Ionosphere on GPS, GPS World, 4, 48-52.

Warnant, R., and E. Pottiaux (2000). The increase of the ionospheric activity as measured by GPS, Earth Planets Space, 52, 1055-1060.

\footnotetext{
${ }^{\star}$ Corresponding author: Wayan Suparta, Universiti Kebangsaan Malaysia, Space Science Centre (ANGKASA), Institute of Climate Change, 43600 Bangi, Selangor, Malaysia; email: wayan@ukm.edu.my.

(C) 2014 by the Istituto Nazionale di Geofisica e Vulcanologia. All rights reserved.
} 